\title{
FURTHER EXPERIENCES WITH INTRAVENOUS AŪREOMYCIN THERAPY. A STUDY OF 116 CASES ${ }^{1,2}$
}

\author{
BY MURRAY SANDERS, JOHN M. RUMBALL, CYRIL SOLOMON, \\ M. GONZALEZ SORET, AND NELDA I. RICCI
}

(From the University of Miami, Medical Research Unit at the V. A. Hospital, Coral Gables, Florida, and the French Hospital, New York, N. Y.)

The need for developing routes of administration for aureomycin other than oral has been apparent since the initial clinical trials with the antibiotic in the early months of 1948 . To fill this need, studies on intravenous aureomycin were carried out simultaneously in the summer and fall of 1948 at St. Vincent's Hospital in New York by Rottino, Sanders, and Philip (1) and at the Harlem Hospital by Hill, Wright, Prigot, and Logan (2). The present report is an extension of the earlier work.

In the study at St. Vincent's, patients suffering from Hodgkin's disease received large doses of aureomycin intravenously up to 4 grams daily and toxicity data were thus obtained since the dosage was pressed until nausea and vomiting occurred. This knowledge has permitted us to proceed conservatively and without ill effects in using the intravenous route for therapy in numerous clinical entities. Detailed results on the clinical studies will be published elsewhere (3). At this time, it may be said that the intravenous method of administration has frequently produced dramatic therapeutic response and has proved to be an entirely practical procedure producing, at therapeutic levels, little or no side reactions.

It is to be noted that kidney and liver function tests made both at St. Vincent's and Harlem Hospitals at no time showed variation from the normal, even after massive doses of aureomycin intravenously were maintained for one week.

\section{Indications for intravenous therapy}

In general, the occasions are fairly obvious when the intravenous administration of aureomycin is

\footnotetext{
1 Presented at the Second National Symposium on Recent Advances in Antibiotics Research held in Washington, D. C., April 11-12, 1949, under the auspices of the Antibiotics Study Section, National Institutes of Health, Public Health Service, Federal Security Agency.

2 Published with the permission of the Chief Medical Director, Veterans Administration, Department of Medicine and Surgery, who assumes no responsibility for the opinions expressed or conclusions drawn by the authors.
}

to be preferred to the oral or intramuscular routes The desirability of rapidly obtaining a high aureomycin blood level with minimum discomfort is clear where :

$a$. fulminating disease is present and the amount of antibiotic required would almost certainly cause gastro-intestinal disturbances;

$b$. the patient does not have the benefit of gastrointestinal absorption because he is vomiting (due to peritonitis, intestinal disturbances, etc.) or because he is in a comatose or semicomatose condition; and

c. the patient has attempted oral medication and has experienced marked discomfort without getting relief from the condition which was the original indication for therapy.

In addition to the extreme circumstances where intravenous aureomycin is urgently necessary, the most common use to which the intravenous method has been put by us is as an adjuvant form of therapy. From the previous blood level studies carried out at St. Vincent's, it was known that aureomycin injected into the blood reached a high level quickly and was also excreted with moderate rapidity (see Figure 1). This fact, as well as our reluctance to use intravenous medication unnecessarily, stimulated the study of combined intravenous and oral medication. It is in this realm that we believe that intravenous administration of aureomycin will find its greatest usefulness.

\section{MATERIALS AND METHODS}

Aureomycin hydrochloride ${ }^{3}$ is a yellow, highly soluble powder available in $50-\mathrm{mgm}$. vials. The procedures for preparing and administering the antibiotic followed in this study have been essentially the same as those recommended by Rottino, Sanders, and Philip. Unless special diluents are being investigated, the contents of each 50 $\mathrm{mgm}$. vial are thoroughly dissolved in about $2 \mathrm{mls}$. of distilled water. If it is necessary or desirable to give

3 We wish to thank the officials of the Lederle Laboratories who so generously supplied large amounts of aureomycin and thus made the present study possible. 
the patient parenteral fluids, the infusion indicated is started. The contents of the desired number of $50-\mathrm{mgm}$. vials of aureomycin in distilled water are then pooled and diluted in proper amounts of $1 / 6 \mathrm{M}$. lactate (Hartman's or Lactate-Ringer's) solution. After thorough mixing, the aureomycin in lactate is given as a rapid infusion. The aureomycin in distilled water is not mixed with the sodium lactate until the infusion is assembled because Harned and his associates (4) found that the antibiotic is stable in an acid medium and loses potency in an alkaline environment.

As far as the amount of lactate for the infusion is concerned, it is our impression that only an approximate quantity is necessary since the lactate merely serves as a vehicle for the antibiotic. It is important to remember that the buffering action of the lactate is helpful since aureomycin hydrochloride in distilled water has an approximate $\mathrm{pH}$ of 3.5 whereas the $\mathrm{pH}$ of the final mixture in lactate is approximately 5.5. The following quantities of 1/6 M. lactate solution as infusion vehicles for aureomycin varying from 50 to $1,000 \mathrm{mgms}$. are suggested. The schedule in Table $I$ is on an entirely empirical basis and is one which has been satisfactory in our hands: 4

TABLE I

$A$ suggested ratio of aureomycin $\mathrm{HCl}$ to $1 / 6 \mathrm{M}$. sodium lactate for intravenous infusions

\begin{tabular}{|c|c|c|}
\hline $\begin{array}{c}\text { Aureomycin } \\
\text { mgms. }\end{array}$ & to & $\begin{array}{c}1 / 6 \mathrm{M} . \text { sodium lactate } \\
\mathrm{mls} .\end{array}$ \\
\hline $\begin{array}{l}1000 \\
350-500 \\
200-350 \\
200 \\
100 \\
50\end{array}$ & & $\begin{array}{r}500 \\
250 \\
150 \\
100 \\
50 \\
20\end{array}$ \\
\hline
\end{tabular}

\section{The bio-assay method}

The bio-assay test for determining the amount of aureomycin in various body fluids was originated at the Lederle Laboratories by Dornbush and Pelcak (5). Since any attempt to study methods of administration depends largely upon an exact adherence to the bio-assay method, care was taken to make certain that the technique used in this study was in complete agreement with the test at Dornbush's laboratory. ${ }^{5}$

\section{Comparative data: intravenous plus oral vs. oral medication alone}

In presenting Figures 1-4 an attempt has been made to cull our experience with 116 patients on intravenous aureomycin therapy so that a basis

\footnotetext{
4 Additional work with intravenous aureomycin since the presentation of this paper has made it apparent that the amounts of $1 / 6 \mathrm{M}$. sodium lactate can be reduced to half those shown here.

5 We wish to thank Messrs. Dornbush and Pelcak for their cooperation and for providing purified antibiotic to be used as standard test material.
}

may be provided for therapeutic manipulation which may be useful in various clinical problems. During recent months, patients received various schedules of aureomycin therapy ranging from a single intravenous injection of $20 \mathrm{mgms}$. in an infant to a combined intravenous-oral course of antibiotic in an adult, in whom the intravenous portion alone consisted of 76500 -mgm. infusions for a total of 38 grams ( 34 days of 500 mgms. b.i.d. and 42 days u.i.d.). In addition to the intravenous medication, 47 grams of adjuvant oral therapy were given. This patient, V. L., is alive and well and is apparently recovering from a chronic disease.

The primary purpose in demonstrating the results of the bio-assay in the following charts is to show the physician how he may proceed in a general fashion in obtaining aureomycin blood levels to satisfy special clinical requirements.

Figure 1 emphasizes the high concentration of aureomycin which can be obtained in the blood following a single injection of 1 gram intravenously. With two hours, a peak of $20 \mu \mathrm{g}$. was reached but there was a fairly rapid drop to $10 \mu \mathrm{g}$. two hours later. Although these high concentrations were not maintained for a long period of time under the given situation, a level of $5 \mu \mathrm{g}$. was present up to 14 hours following the injection. This, of course, is a significant level which would be more than sufficient to combat most infections. Even after 24 hours, a significant level of $2 \mu \mathrm{g}$. resulted. The technique of injection of 1 gram at a time appears to have little hazard judging the ease with which ten patients received such injections.

The advantage of using oral therapy in combination with intravenous therapy is illustrated in Figure 2. When compared with a single intravenous injection of 1 gram, the smaller intravenous injection of $350 \mathrm{mgms}$. given in conjunction with 250 mgms. by mouth every four hours produced significant blood levels which fluctuated between 3.2 and $6.4 \mu \mathrm{g}$.

If this comfortable oral and intravenous schedule is continued for 24 hours (Figure 3), we see a dramatic rise to $12.8 \mu \mathrm{g}$. with an excellent maintenance of aureomycin concentration for as long as 12 hours after cessation of therapy. Figure 3 also illustrates the difference between the oral regi- 


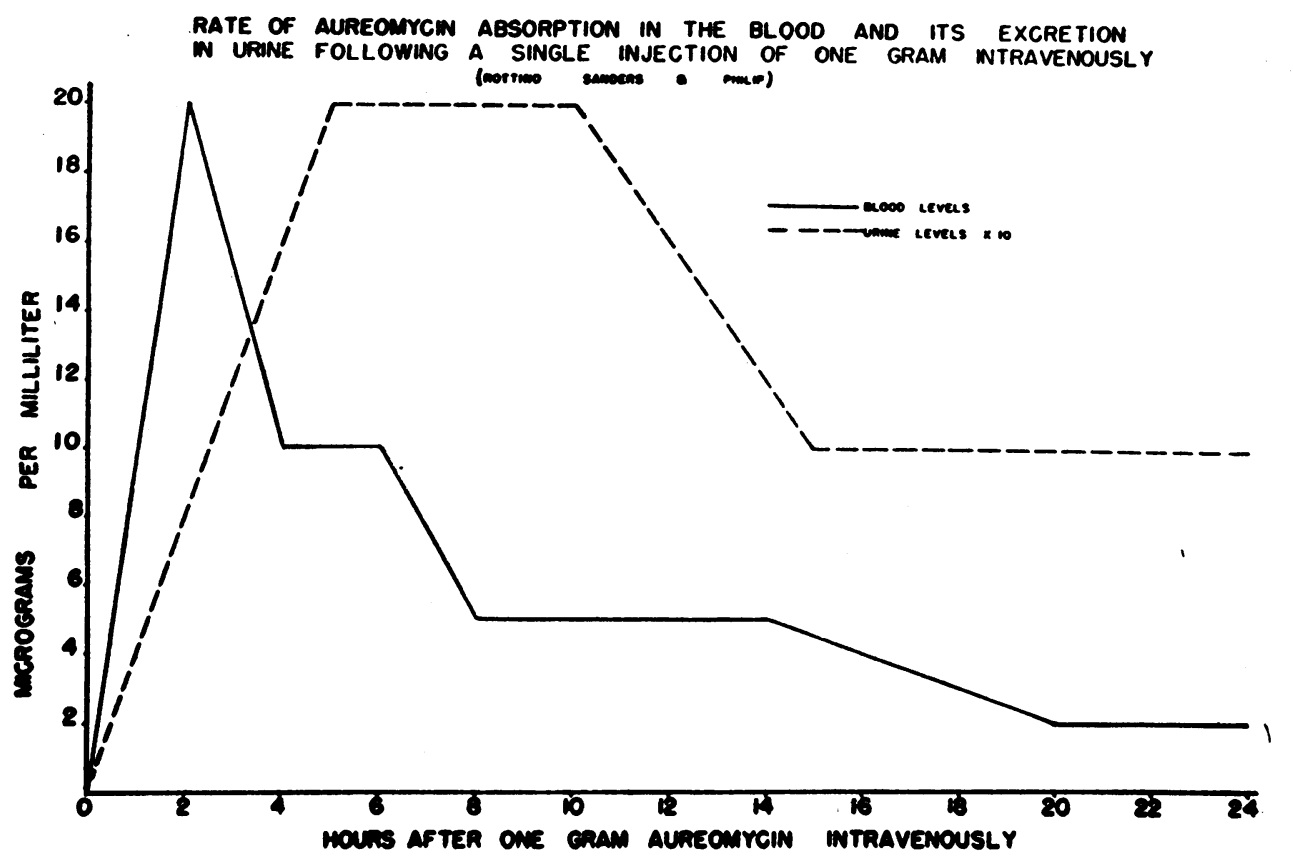

Fic. 1

men of 250 mgms. every four hours and the com- within 12 hours after the first capsule is taken that bined oral-intravenous schedule. On the oral a concentration of $4 \mu \mathrm{g}$. per $\mathrm{ml}$. is reached in the therapy there is a slow rise with the level not ex- blood. The peak of $5 \mu \mathrm{g}$. is reached and mainceeding $2 \mu \mathrm{g}$. for the first ten hours. It is only tained from 18 to 34 hours.

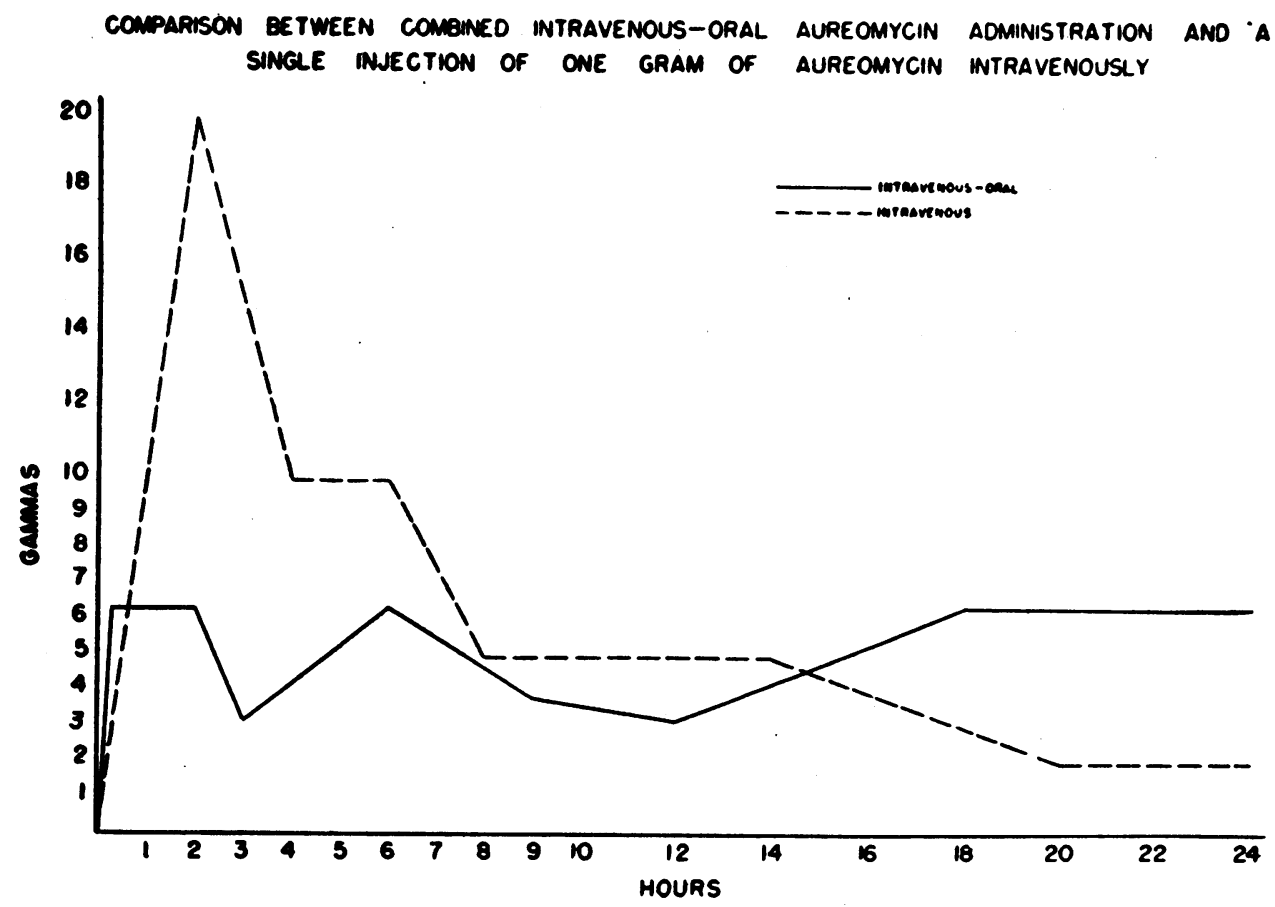

FIG. 2 
COMPARATIVE BLOOD LEVELS

FOLLOWING ORAL ANO INTRAVENOUS-ORAL ADMINISTRATION OF AUREOMYCIN

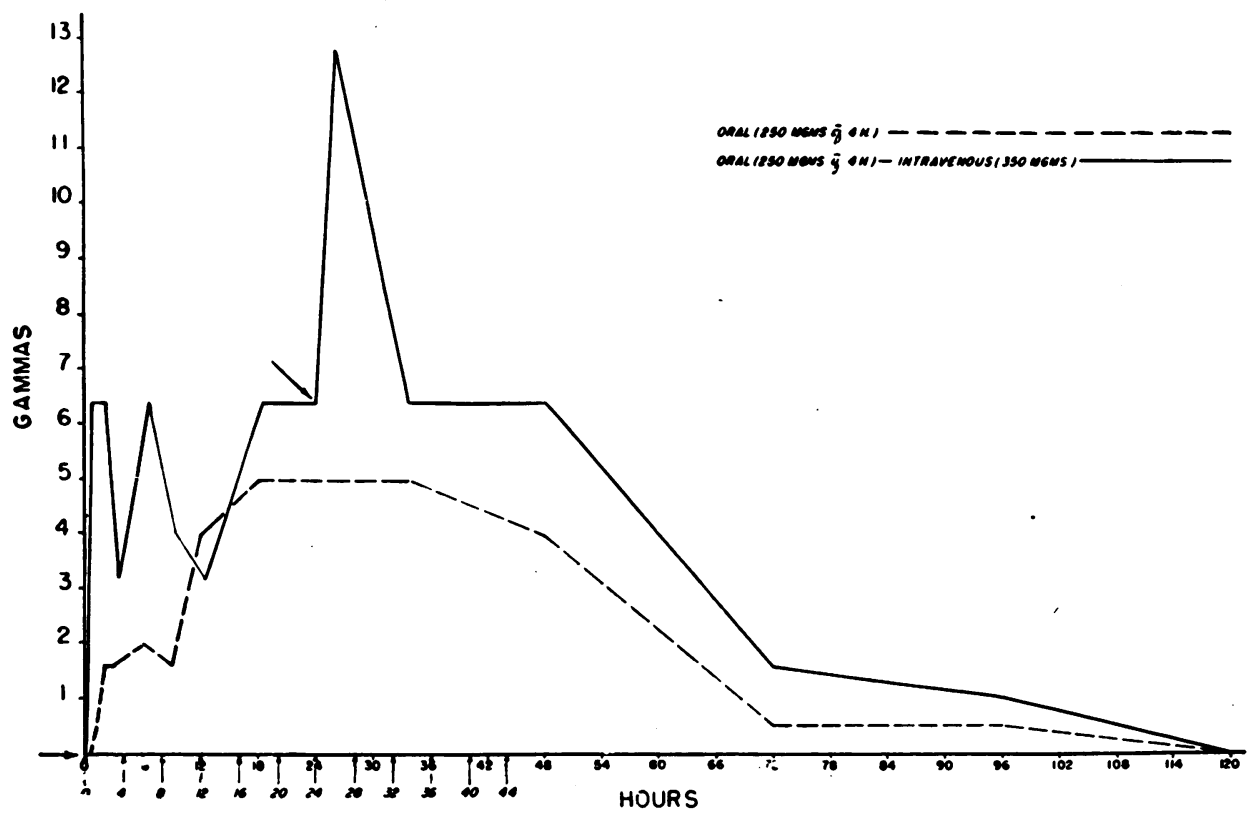

FIG. 3

By utilizing the information in Figures 2 and 3, variation to similar dosage schedule has been it should be possible to maintain aureomycin con- observed with penicillin and streptomycin therapy. centrations at any desired level, subject, of course, That the same factor must be considered in aureoto individual variations. The factor of individual mycin therapy is apparent from Figure 4. The

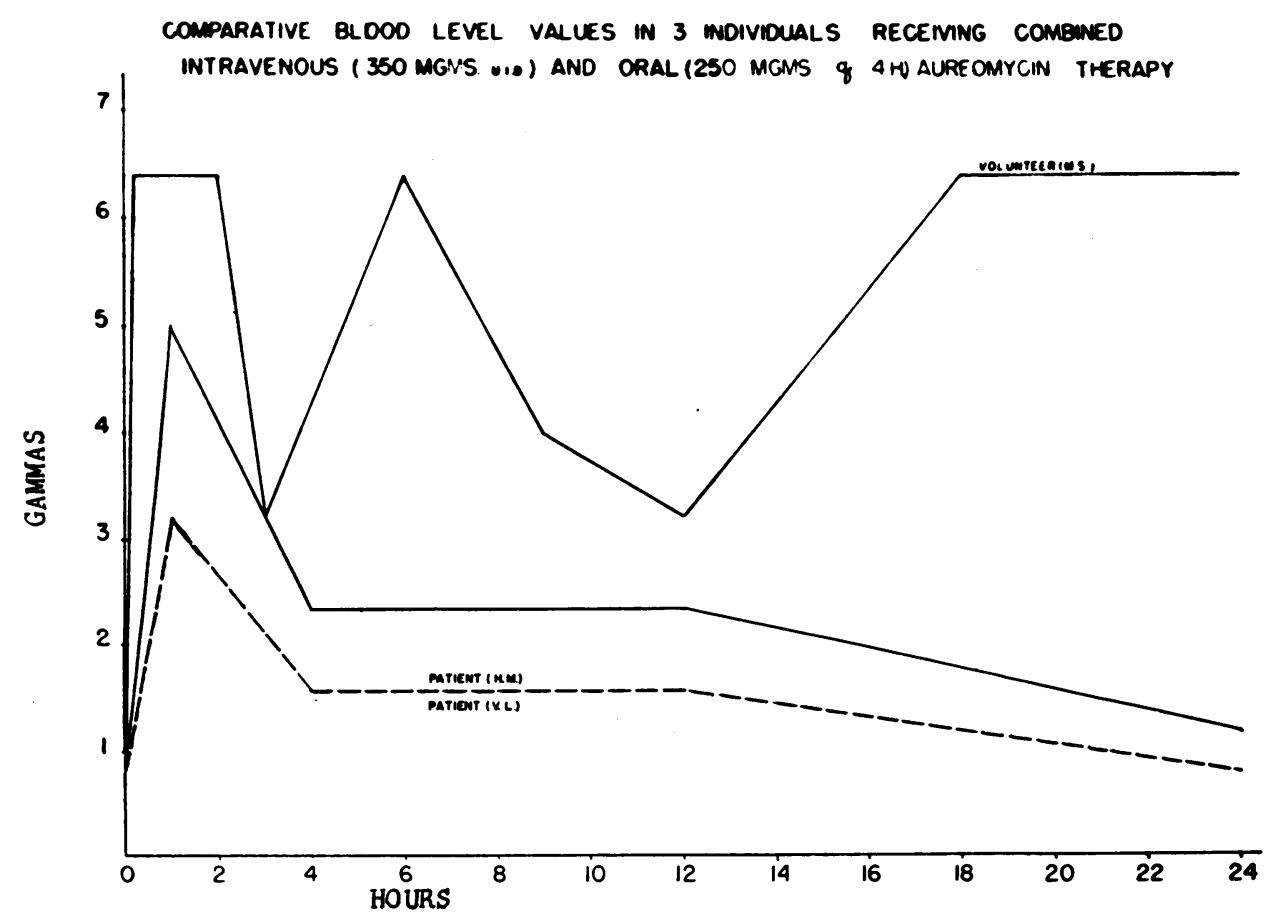

FIG. 4 
volunteer, M. S., was not a demonstrably ill individual and reached a peak concentration of 6.4 $\mu \mathrm{g}$. in his blood within 20 minutes after the intravenous injection of $350 \mathrm{mgms}$. This level fluctuated during the next 24 hours between 3.2 and $6.4 \mu \mathrm{g}$. In contrast, patient H. M., suffering from infectious mononucleosis, and patient V. L., a post-hepatitic cirrhotic, who were on the same intravenous and oral schedule as the volunteer, reached a peak of $3.2 \mu \mathrm{g}$. and a maintenance level of between 1 and $2 \mu \mathrm{g}$.

Enhanced aureomycin blood levels by the use of caronamide

Since it has been shown that the blood concentration of penicillin can be enhanced by the oral administration of caronamide (6), an attempt was made to ascertain the effects of this drug (4Carboxyphenylmethansulfonamide) on aureomycin absorption. To date, three ${ }^{b}$ patients have been studied and the result suggests that caronamide raises the blood level of aureomycin.

6 A temporary shortage of parenteral aureomycin has limited the number of patients under study with caronamide.
This phase of the work has been of particular interest to us since the assumption has been made by Beyer ( 7 ) that the action of caronamide in relation to penicillin absorption depends on the blockade by caronamide of specific enzyme systems responsible for penicillin transport through the renal tubules. Strauss, Richburg, Saba, and Alexander (6) have stated that caronamide has no effect on the plasma concentration of streptomycin when the antibiotic is given in multiple intramuscular injections. Inasmuch as aureomycin and streptomycin are derived from related microbial sources, it is curious that an enhancement action has been demonstrated.

One of the first patients to receive caronamide, 4 grams by mouth every four hours, was H. M. As is apparent from Figure 5, the increase of the aureomycin level following the use of caronamide was not dramatic, since a peak of $4 \mu \mathrm{g}$. was reached in association with caronamide as against a peak of $3.2 \mu \mathrm{g}$. when aureomycin was used alone. It may be significant that in the last 12 hours, a level of $2 \mu \mathrm{g}$. was maintained when caronamide was given with the aureomycin, whereas without this adjunct the aureomycin level dropped to less than $1 \mu \mathrm{g}$.
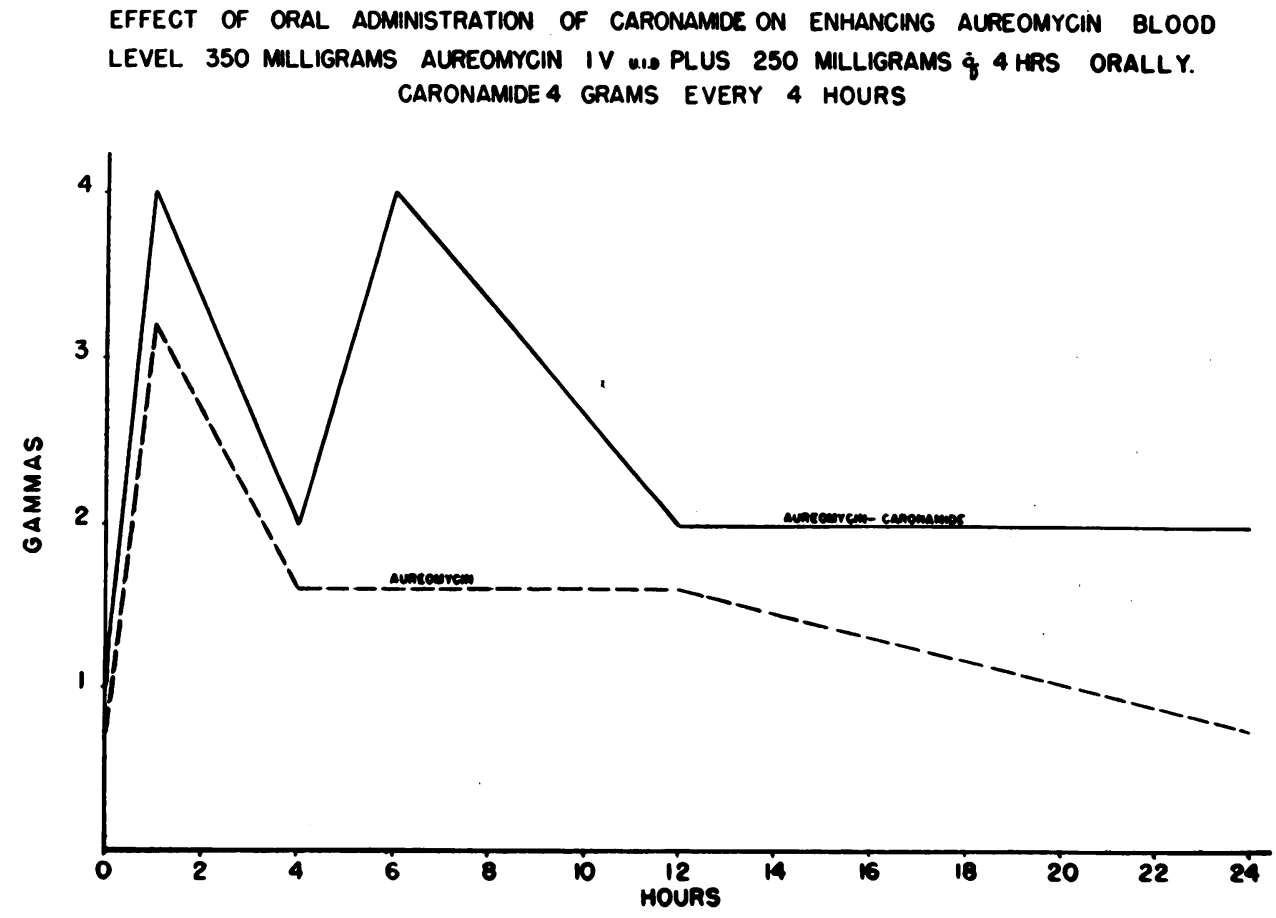

FIG. 5 


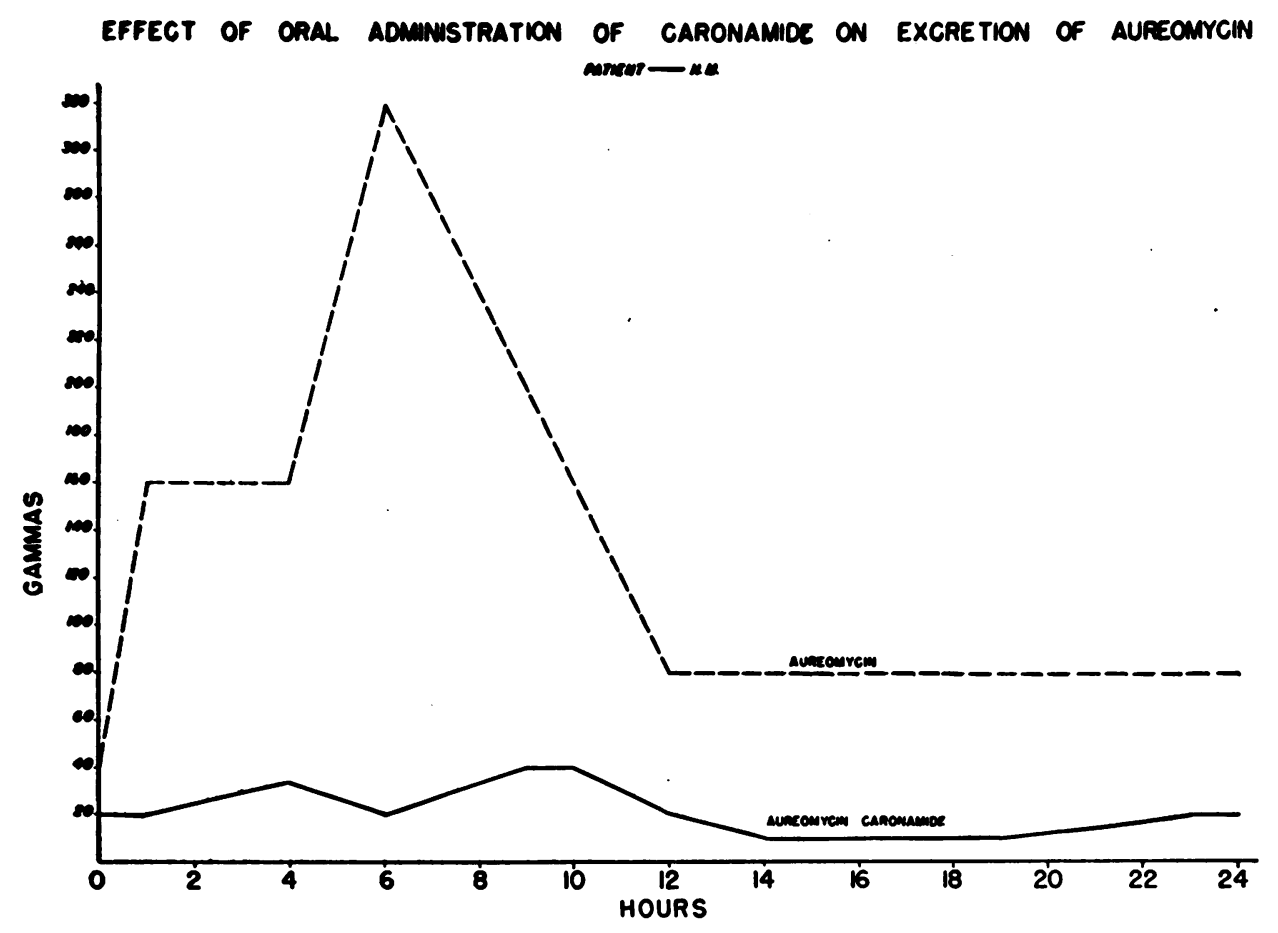

FIG. 6

Of much greater significance was the suppression of the urinary excretion of aureomycin in the same patient, $H$. M., when caronamide was given (Figure 6). With the use of the chemical, the highest point of excretion was only $40 \mu \mathrm{g}$. in nine and ten hours. Against this, a peak of $320 \mu \mathrm{g}$. per $\mathrm{ml}$. in the urine was observed in six hours after initiation of therapy when the antibiotic was used alone.

In the case of patient V. L., a more significant response of the aureomycin to the caronamide was noted (see Figure 7). Again, 4 grams every four hours of caronamide were given by mouth. Within one hour after an intravenous injection of 350 mgms. and one capsule of $250 \mathrm{mgms}$. by mouth, the blood level was $6.4 \mu \mathrm{g}$. per $\mathrm{ml}$., decreasing within the next three hours to $3.2 \mu \mathrm{g}$. Under the same circumstances but without caronamide, a blood level of $3.2 \mu \mathrm{g}$. with a drop to $1.6 \mu \mathrm{g}$. in three hours was attained.

In a third patient, L. M., the effect of caronamide on aureomycin absorption and excretion was not that of enhancement. Whether this was due to individual variation or whether it was due to the fact that the aureomycin was given orally remains to be seen.

\section{Complications of intravenous therapy}

In the original studies by the St. Vincent's Hospital group, the complications attendent upon intravenous aureomycin therapy were listed as being nausea or vomiting and phlebitis. In contrast, the Harlem Hospital workers noted little side reactions of any type after intravenous therapy.

In the present study, no gastro-intestinal difficulties were encountered which could be attributed to the intravenous medication. This was not surprising since the nausea and vomiting seen in St. Vincent's Hospital accompanied only intravenous doses of 1.5 grams or over, whereas it is apparent that satisfactory therapeutic levels have been obtained in our work with daily intravenous medication not exceeding 1 gram. In most instances, even this level of intravenous medication was unnecessary.

The most consistent sequela of intravenous therapy has been a phlebitis. From our experience involving 116 patients, two facts have become apparent. In the first place, there appears to be a marked personal factor. Some patients react quickly whereas in other instances the phlebitis does not appear until numerous injec- 
TABLE II

Phlebitis following intravenous aureomycin therapy

\begin{tabular}{c|c|c|c|c|c}
\hline \hline Group & $\begin{array}{c}\text { Number } \\
\text { of } \\
\text { patients }\end{array}$ & $\begin{array}{c}\text { Number } \\
\text { of } \\
\text { injections }\end{array}$ & $\begin{array}{c}\text { Mgms. } \\
\text { per } \\
\text { injection }\end{array}$ & Phlebitis & $\begin{array}{c}\text { No } \\
\text { Phlebitis }\end{array}$ \\
\hline I & 60 & $6-15$ & 200 to 250 & 28 (mild) & 32 \\
II & 35 & $1-5$ & 250 to 350 & 0 & 35 \\
III & 21 & 15 to 76 & 250 to 500 & 21 & 0 \\
\hline
\end{tabular}

tions have been made into the vein. Secondly, the amount of aureomycin which is injected into the vein appears to have some bearing on the formation of phlebitis.

The 116 patients who received aureomycin intravenously reacted in the following fashion (see Table II).

Although many of the patients who received the antibiotic intravenously showed a phlebitis, in the majority of instances the tenderness, induration and rigidity of the vessel disappeared within periods ranging from a few days to several weeks.

The whole problem of phlebitis was to some extent minimized when care was taken to attach intravenous infusions only after sharp needles were well into the veins. Another helpful point of technique was the practice of following the simple fundamentals of intravenous therapy; i.e., giving the first infusions in distal veins, later injections proximally, and varying the sites of injection by using alternate hands and arms. As a matter of fact, phlebitis has never been sufficiently serious to prevent a patient from receiving several injections. It is only the hypersusceptible individual who is unable to receive many injections. Occasionally, when numerous infusions are required, the presence of phlebitis makes continued therapy difficult or impossible.

One other complication was noted in three of the 116 patients. In one instance, the patient experienced a chill resulting in a fever of $101^{\circ}$ within one hour after the intravenous administration of aureomycin. The chill was moderately severe and the fever lasted approximately one hour. Repetition of the infusion the next day produced essentially the same reaction in this patient and oral medication was instituted in place of the infusions. In a second patient, a similar reaction occurred, the fever going to $105^{\circ}$; when intravenous medication was cautiously continued in this instance, however, no further reaction was observed and the patient was able to take a course of 15 injections of $500 \mathrm{mgms}$. each without fur-

EFFECT OF ORAL ADMINISTRATION OF CARONAMIDEON ENHANCING AUREOMYCIN BLOOD LEVEL. 350 MGMS AUREOMYCIN IV, U.1.0. PLUS 250 MGMS $\dot{\text { f }} 4 \mathrm{H}$ ORALLY. CARONAMID 4 GRAMS $\bar{q} 4 \mathrm{H}$

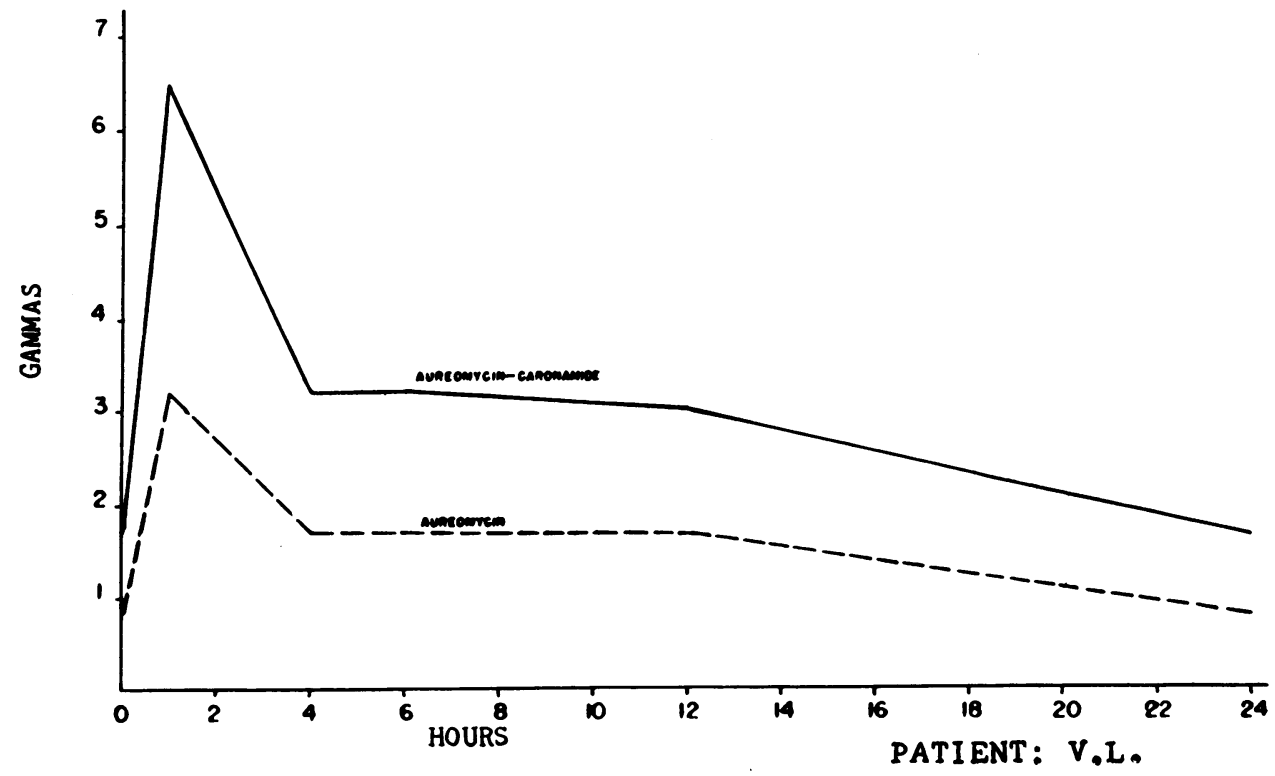

FrG. 7 
ther untoward reaction. In a third patient, who had a fever of $103^{\circ}$ before the infusion was administered, there occurred a chill and rise in temperature to $105^{\circ}$ four hours after the infusion. A repetition of the process on the following day made us reluctant to use further intravenous therapy, particularly since the patient was able to take aureomycin by mouth.

Aureomycin has shown little capacity to produce sensitization. Nevertheless, it must be borne in mind that it is only a matter of time before the patient is found who will show allergic manifestations to this antibiotic. While no serious reactions were encountered in our series of $116 \mathrm{pa}-$ tients, it has been noted that cessation of therapy was necessary in two instances where chills and fever followed the antibiotic infusions.

Since reactions have been so infrequent and of a relatively mild nature, we believe further investigation is warranted regarding the advisability of using an initial test dose of $50 \mathrm{mgms}$. or less in each patient, before an active therapeutic schedule is begun by vein.

\section{CONCLUSIONS}

1. The technique for administering aureomycin intravenously and indications for its use are discussed.

2. Blood concentrations and urinary excretions under several intravenous-oral and oral dosage schedules are submitted.

3. Absorption of aureomycin in the blood appears to vary with the individual.

4. It is suggested that caronamide may enhance blood levels of aureomycin and that it definitely decreases excretion of the antibiotic through the kidneys.

5. No serious toxic effects have been noted following intravenous aureomycin therapy. Only two of the 116 patients experienced febrile reactions. These reactions appeared to be of an individual nature since the same production lots failed to evoke reactions in other patients.
6. With the preparation of aureomycin now available phlebitis occurred in 30 to 40 per cent of the patients when the antibiotic was given intravenously.

7. Nausea and vomiting were not encountered as direct concomitants of intravenous therapy in this study. Gastro-intestinal symptoms were not noted even in a patient who had received 76 500-mgm. injections by vein.

8. We are of the opinion that intravenous aureomycin is a necessary mode of administration in some instances and a desirable one in others.

\section{ACKNOWLEDGMENTS}

We wish to express our appreciation to the attending and resident staffs of the following hospitals for their efforts in providing material and for assisting with the observations: V. A. Hospital, Coral Gables, Fla.; Jackson Memorial Hospital, Miami, Fla.; St. Francis Hospital, Miami Beach, Fla.; Alton Road Hospital, Miami Beach, Fla.; French Hospital, New York City; and St. Vincent's Hospital, New York City.

\section{BIBLIOGRAPHY}

1. Rottino, A., Sanders, M., and Philip, W. E., Use of aureomycin intravenously. In preparation.

2. Hill, H. M., Wright, L. T., Prigot, A., and Logan, M. A., Clinical studies of aureomycin. In preparation.

3. Rumball, J. M., Sanders, M., and Solomon, C., Clinical experiences with aureomycin. To be published.

4. Harned, B. K., Cunningham, R. W., Clark, M. C., Cosgrove, R., Hine, C. H., McCauley, W. J., Stokey, E., Vessey, R. E., Yuda, N. N., and Subba Row, Y., The pharmacology of duomycin. Ann. New York Acad. Sc., 1948, 51, 182.

5. Dornbush, A. C., and Pelcak, E. J., The determination of aureomycin in serum and other body fluids. Ann. New York Acad. Sc., 1948, 51, 218.

6. Strauss, E., Richburg, P., Saba, P., and Alexander, J. E., Enhancement of plasma penicillin concentrations by caronamide and sodium benzoate. J. Lab. \& Clin. Med., 1947, 32, 7.

7. Beyer, K. H., New concepts of competitive inhibition of the renal tubular excretion of penicillin. Science, 1947, 105, 94 . 